\title{
Article \\ A Critique of Volition: An Alternative Doctrine of the Will and Intellect Reconciling that of 17th-Century Rationalist Philosophers Descartes and Spinoza
}

\author{
La Shun L. Carroll ${ }^{1}$ \\ 1
}

Keywords: Metaphysics; Ontology; Volition; Intellect; Freedom; The Will

\section{Abstract}

The will and intellect have been debated philosophically without resolution for centuries. It is for this reason that this article considers doctrines of the will and intellect of two $17^{\text {th }}$-century rationalist philosophers, Rene Descartes, and Baruch Spinoza, both of whom were chosen as the focus for analysis because of their prominence and contrasting views. Our objective was to critique the doctrine of the will and intellect to develop an alternate theory that expounds on their previous work. A qualitative exploration was undertaken that compared their respective belief systems of Dualism and Monism. Despite their strengths of their arguments, an analysis of Part V of Spinoza's Ethics and Discourse on Method and Meditations on First Philosophy by Descartes led the author to determine that both were partially correct in their positions yet consistent with one another. From this conclusion, and building upon their work, this article presents the synthesis of the author's alternate theory regarding the qualitative characteristics of both the will and intellect. An ontological argument against the existence of infinite entities as a corollary with the implication that neither the will, intellect, nor God can be infinite. While the limitation of the conclusions drawn is that they are dependent on the author's philosophical framework, the originality of this paper is based on the author's synthesis of one coherent theory from two philosophers espousing contrasting theistic systems and should serve as the foundation for future exploration and debate.

\section{Introduction}

As an idea, freedom of various peoples has been lost and won numerous times at the hands of other people. Used as a common means to particular ends, when not employed an end in itself throughout history, any such imposed limitations on the freedom of others has been relatively evanescent. Ironically, it was one group of "civilized" humans exercising their supposed free will when they enslaved another civilization during various periods throughout history.

Both real and perceived threats that potentially jeopardized a nation's continued ability to enjoy its freedom have been sufficient to encite quarrels on various levels historically. In an effort to maintain peace and protect the freedom of a nation's people documents such as the U.S. constitution were constructed with regard to "free speech," organizations such as the American Civil Liberties Union, and Icons including the Statue of Liberty are indications of the importance societies place on exercising free will. While hundreds of thousands of lives, if not millions, have been lost in the name of defending the right to exercise one's freedom, despite its occurrence being self-substantiating, there is something troubling about nature of exercising freedom conceptually: the free will of some may be exercised to deprive that of others.

Ultimately, either free will exists or it does not and we may never be able to demonstrate either. However, if there exists at least one instance in which free will can be demonstrated not to have existed as exemplified by any single account, then we must not only accept that it does not exist for that individual, but if it did not exist in one case for one person because of another, then perhaps it is 
possible that the free will of one was not to blame for its own deprivation in another. In order to maintain consistency, both captor and captive ought to be able to express their respective free will simultaneously or be unable to do so in all scenarios. Unfortunately, the same scenario may be used to justify either case but be self-refuting when used. It may be determined that what is referred to as free will may neither be said to exist nor not to exist, which is why we turn to documented accounts of belief regarding freedom of the will.

Of those who documented their beliefs about free will, none has delved more deeply into the matter than the philosopher. Philosophers and philosophy, from the Greek for "love of wisdom" or "friend of wisdom," are concerned with knowledge of a variety of different subjects and study both general and abstract features of the world [1]Much of civilization's progress has been a result of formulating theories and positions that have contributed significantly to bodies of knowledge that still are flourishing today.

The topic of free will and the intellect may be approached from a variety of philosophical frameworks, which depend on what aspect is of interest to the philosopher conducting the research. For the purposes of the present study, the main research questions were whether the will exists and how it could be known. Based on these questions it is Ontology, Metaphysics and Epistemology, which comprise the philosophical framework with which the paper will address the topic. Ontology, originally from the Greek meaning "being; existence," is the branch of Metaphysics devoted to investigating the nature of what exists [2] Additionally, Metaphysics concerns what is real or the nature of reality and of being [3] (Blackburn, 2008), which naturally subsumes Ontology. Lastly, Epistemology concerns the theory and nature of knowledge and how it is acquired [4] (Blackburn, 2008).

Epistemology may be divided into two schools of thoughts. There are those philosophers who believe that knowledge may be achieved through the senses and experience to whom we referred as empiricists (Blackburn, 2008). Conversely, philosophers who think that the way to knowledge is through reasoning are known as rationalists (Blackburn, 2008).

In this paper, the work of two philosophers who espoused theories of epistemology from the school of rationalism will be critiqued: Rene Descartes and Baruch Spinoza. Descartes' Discourse on Methods - Meditation on First Philosophy was the source used for his doctrine of the will. Spinoza's Ethics was referenced as the source for interpretation of his writings on the will. Both sources were obtained as found in Cahn's Classics of Western Philosophy [5] (Cahn, 1995). It is not possible to cover every known work or opinion on topic, so it should be understood that there are limitations of any results herein concluded because they were based on the interpretation of the author and on the sources used.

\subsection{Structure of This Article}

Thoroughly understanding the conclusions drawn in this article is as important as understanding the philosophical framework from within which they were drawn. Therefore, this article will begin with the philosophical worldview mind-mapping of the author's philosophical construct as it relates to the arguments and approach presented herein. In the first half of the article, we will introduce Descartes' doctrine of the will and the intellect followed by a discussion. Next, we will present the viewpoint of Spinoza regarding the doctrine of the will followed by a discussion. After that, we will compare the doctrines to one another and search for consistency. The findings will then serve as the foundation for the second half of the article devoted to the interpretation of each philosopher's position in addition to the author's proposed alternative perspective. Lastly, we will conclude with an ontological argument against the existence of infinite entities and its implications.

\subsection{Author's Philosophical Worldview}

The author is inclined to withhold assent to any proposition that is non-evident, as would a Pyrrhonian Skeptic. Nevertheless, he adheres to an epistemological theory of knowledge that is grounded in foundationalism, but consists of core beliefs taken as axioms that are evident from a blend of both rationalism and empiricism. Additionally, the author is an externalist about justification but 
views both internal as well as external factors as capable of affecting one's justification for belief. The author makes the distinction between knowing, the justification for believing what one knows true, knowing to be true, and the object of knowledge actually being true.

Although there may or may not be an inherent truth-value in the objects of knowledge (e.g., that person to be good), knowing is not the same as justification or knowing to be true, nor is it the same as what is actually known being true itself. The relative nature of truth and falsity has resulted in the author adopting a propositional attitude toward knowledge that is skeptical about knowledge truth because of skepticism about knowledge truth-aptness. Skepticism, as it was originally interpreted, was centered around the value of inquiry or questioning things and the author questions whether knowledge is the sort of thing that can be inherently true or false universally.

Lastly, the author holds an anomalous monism position regarding property dualism. Therefore, whenever the mind/body, mental/physical, finite/infinite, or any similar characteristic representational distinction is made in this article, the author intends them to be understood as that between the will and intellect would be possible without at least briefly mentioning the philosophical positions of Dualism and Monism as they pertain to this article. Dualism in the philosophy of mind stresses the extreme difference between the mind and matter [6] (Calef, n.d.). Although it is not the purpose of the present undertaking to consider, there also exists a dichotomy within the dualistic system of belief that refers to that which concerns either the existence of multiple substances, or that of more than one property [7].

Properties may be any number of adjectival descriptors and are what usually characterize substances. That notwithstanding, that which is characterized is not necessarily equivalent to the properties that characterize it. The belief in the existence of more than one (e.g., two) substance for properties to characterize is referred to as substance dualism. Substance dualism is what concerns this discussion because, with respect to Descartes, it is denied that the mind and the brain are the same (substance) yet both are that to which properties may be attributed.

Monism is a view of the universe as a unified whole and concedes no distinction between the brain and the mind [8] (Schaffer, 2014). Monists believe that both mind and matter are one and the same thing conceived in two ways. As it pertains to a dualistic position there may be difficulty in defending it when one tries to explain the manner in which the mind and body interact if they are truly separate and distinct. This difficulty one finds such a position also extends into describing the interaction between both the will and the intellect, which Descartes believed were to be distinct as well. Nevertheless, while obviating the problem of dual substance interaction, monism may not entirely account for the realm of what one may observe and introduces other unanswered onto-epistemological questions.

\section{Descartes' Doctrine of the Will}

According to Descartes' theory of the will, many things may be explained by the interplay between both the will and the intellect. As an example, he believed that the interplay between volition and understanding was at the core of the process of erring. That is, the reason we err is because our volition (i.e., will) extends beyond our understanding (i.e., intellect). Furthermore, the will, as well as the intellect, are separate and discernible from one another according to Descartes [5] . Given the distinction between the two entities, one way of interpreting the extension of the will beyond that of the understanding is to view the will as infinite while accepting the understanding as finite.

Descartes believed that willing is simply a matter of being able to do or not to do the same thing. Being able to affirm or deny, and to pursue or to shun, would also be considered a task for the will. When something is proposed to us by our intellect it is so that we may affirm or deny it. Our intellect has a way of making us feel as though we are moved in such a way that is determined if we have a good and clear understanding. According to Descartes, possessing a good understanding by means of a thorough conception of it leaves the will no choice other than to select that which it will be inclined 
to choose [5]. That notwithstanding, even in the absence of an in-depth concept of good and a true understanding the will may still select, which is what leads us to err.

Descartes claimed that the intellect is finite, and that it is through the intellect that we perceive ideas. These ideas are that about which we render a particular judgment through exercising the will. Interpreting ideas in this manner, error may neither be attributed to the mind nor to God; the error is to be found in a lack of intellect and attributed to our will, which extends way beyond our intellectual capacity [5] .

While we have learned that the will and the intellect are different according to Descartes' belief, that which originates in the mind and what is manifest in the body are not one and the same. How the mind and body (e.g., intellect and will) interact is up for debate. Given the doctrine of Descartes followed his Dualistic position, the distinction between the mind and the body, or will and intellect, has left their interaction unresolved.

\section{The Will and the Intellect According to Spinoza}

Although Descartes claims that one can will, that is, affirm or deny, something beyond one's intellect, Spinoza presents a convincing argument that challenges his assertion. Spinoza argues that a particular volition and an idea are one and the same thing, which effectively neutralizes Descartes' statement if he is correct.

The author claims that the will is neither completely free, nor infinite. If the will were infinite, then one ought to be able to affirm or deny without an idea. That is, to say, affirming or denying would not be dependent on the presentation of an idea; the act itself would suffice for it to exist or cease doing so, which is not possible. One affirms or denies ideas, and affirmation or denial is about ideas. Without an idea, there can be no affirmation. In effect, the will is neither infinite, nor free to do as it chooses; it is finite and concerned only with the particular idea.

Spinoza claims that both the will and the intellect are one and the same. The will and the intellect being the same is naturally in complete accordance with Spinoza's monist view. Furthermore, the will and intellect being the same implies that they are indistinguishable from one another. Such a position makes it apparent how much Spinoza's position shaped his approach to addressing the issue of the will and the intellect. Unlike Descartes' Dualistic approach, Spinoza's belief in the existence of one substance obviates explaining how a mind and body are to interact, which make this theory appealing.

Spinoza believed that the faculty of willing could not extend further than the faculty of perceiving or conceiving, which he claimed because the will, like perception, requires an object. In other words, one cannot will something that he or she does not conceive or perceive. Simply stated: that which one cannot grasp, one cannot will. Thus, it is not possible to will that which is not seen by the intellect, or for the will to extend beyond the intellect. If the will were to be infinite, then it would neither require cause nor depend upon anything. Nevertheless, it is unquestionable that ideas involve either affirmation or denial, and the affirmation or denial of an idea is entirely dependent on that idea. Absolute free will would be to affirm or deny without an idea, which would be impossible, according to Spinoza's doctrine.

Deception is based strictly on assent/affirmation or denial/negation, which is the domain of the will. As an example, perceiving a winged horse is not deception according to this definition. However, assenting to, or affirming the existence of, a winged horse would be considered being deceived. The reason that affirming a winged horse would be deception is that one cannot truly assent to the existence of, or affirm, that which one does not perceive. Spinoza claimed that a particular volition (i.e., assenting to or affirming something), and the idea being affirmed (i.e., a winged horse) were the same thing. Therefore, perceiving a winged horse would be the same as affirming a winged horse exists, which demonstrates how the will may extend beyond what one knows through the intellect.

Whether it would be possible to affirm something that one does not perceive is something that is worthy of inquiry. If affirmation is implicit in perception, then there is no way to perceive what one does not affirm or to which one does not assent. In other words, that something is perceived intimates 
at the fact that it is claimed by the one perceiving, or else it would not have been perceived. Thus, it appears as though affirming through the will that which one does not claim to perceive is not possible.

That only affirmed ideas make it to the stage of being perceived seems to be a reasonable concession to make. It can also be deduced from this that since only affirmed ideas are perceived, denied ideas never exist. Furthermore, if true that one can only affirm ideas, then there must exist an affirmation before denying could be possible. As an example, to say that an $\mathrm{x}$ is not a cat, or to deny the fact that $x$ is a cat, one must first know what a cat is prior to stating what it is not. Without knowing first what a cat is, how could one say what it is not? Furthermore, for every comparative denial, there is, at least, one implicitly different affirmation following from Spinoza's doctrine. Therefore, to deny that $x$ is a cat, by comparison, one now affirms what $x$ is such that one can subsequently state what is not an $x$ when compared to $x$.

The problem of explaining the interaction between the will and the intellect, which was modeled after his belief as a monist, does not exist. The Mind and Body are one, and so are the will and the intellect. According to Spinoza, everything in this physical world has a mental counterpart. Nevertheless, as will be discussed in subsequent section in this paper, mental and physical should be understood as properties. Moreover, with the sole exception being those that naturally occur including animals, plants, and the result of natural substances like the elements, minerals, and water undergoing processes to yield tangible things (e.g., rocks or caves) the author claims that all other things inter-subjectively deemed physical have the mind (i.e., thought) as their origin, but are not the same. In other words, even though all of these physical things except naturally occurring examples may have a mental counterpart, the mental counterpart had to precede them. If the mental counterpart did not precede the physical counterpart and it is accepted that these physical things have mental as its origin, then, there would be no physical.

There is no doubt that Spinoza believes that the will and the intellect are the same. That notwithstanding, if this is the case then either they are both finite, or they are both infinite. If they are both infinite, then one would not need the other, or they would both come to be at the same time. However, this cannot be possible. The author does agree with Spinoza that the physical has the mental as a counterpart. Nonetheless, the author claims that if everything physical has a thought as its origin, or if the mental precedes the physical, then they cannot be equivalent because this implies that the physical depends on the mental as its precursor. Furthermore, the mental would have no precursor other than itself.

Claiming that the mental and the physical are equivalent would be analogous to stating that the cause and the effect of something are the same, which entails that both could occur simultaneously were one to believe in causality. In addition, if as properties, the mental precedes the physical, then the mental exists without any cause other than itself. If the mental does exist without a prior cause, then it would be something that is considered infinite because the mental would be independent, cause itself, and be the cause of the physical. According to this line of reasoning, the physical would be contingent upon the prior existence of the mental.

For Spinoza, the will cannot extend beyond the intellect because they are one and the same. Willing, which consists of affirming or denying, is equivalent to perceiving since both require an object. In other words, one cannot will that which he or she cannot perceive; what one cannot grasp one cannot will. Therefore, the will and the intellect are equal like the view of the mind and body in monism. Nonetheless, the author argues that for every denial, there is an affirmation; the denial does have an affirmation as its precursor, however.

\section{Interpretation and Critique}

In comparison, the respective doctrines of Descartes and Spinoza appear to be opposing one another. Descartes was a Dualist and, according to his system of belief, the mind and the body exist as discernible entities. Thus, according to Descartes' doctrine, it should not be surprising that the will and the intellect are viewed as distinct. Furthermore, the will would be interpreted as infinite while 
the intellect would be finite. As a whole, the resemblance of aspects of the doctrine of the will with Descartes' dualistic system of belief that the mind and body are different is undeniable.

Conversely, Spinoza is a monist who believes that the mind and body are a unitary whole. Additionally, he believes that for everything physical there is a mental counterpart. Concerning Spinoza's doctrine of the will, the manner in which he approached it was determined, or at least structured around, his monistic system of belief. The structure based on monism should be obvious in that Spinoza believes that the will and intellect are one and the same, which reflects his view regarding the mind and body. Furthermore, despite initially understanding erring as a volitional issue, it was determined that affirming (i.e., willing) by granting the existence of something is tantamount to perceiving it.

In both Descartes' and Spinoza's doctrines, their arguments parallel their respective systems of belief identically and neither contradicted them. That notwithstanding, despite Spinoza clearly making some valid points, the author still finds a problem with conceding that the will and intellect are the same. Moreover, the author also is not in agreement with Descartes' argument entirely, as the will and intellect are not different either. Since the will and the intellect cannot both not be the same yet both not be different, in order to reconcile this apparent absurdity, we must elaborate of what is meant by sameness and difference. To do this, we need to turn to the realm of properties and revisit the will.

To state that something is the same or different is very vaguely descriptive at best. Instead of merely claiming sameness or difference, it would be more accurate and helpful to explain precisely how one determines such sameness or difference. A satisfactory explanation may be achieved through the establishment of criteria that will be used in order to classify. The criteria that were chosen for classifying sameness and difference were qualitative characteristics and quantitative characteristics, which are more accurately described as being properties. Everything has a set of properties comprised of either qualitative or quantitative characteristics and the will and the intellect are no exceptions.

\section{Properties and the Distinction Between Sameness and Difference}

The author's disagreement with Spinoza's position with regard to the will and intellect in favor of them reflecting oneness, as well as with Descartes' argument for their fundamental existence as a duality, stems from the notion of properties. A property, in logic and metaphysics, is an attribute or characteristic, universal that may belong to one thing or many things [7]. For instance, examples of properties may include being finite, being infinite, being the same, or being different. It is through the use of such properties that we may clarify and determine the class to which they belong.

Spinoza did not make explicit whether both the will and intellect were equally finite or equally infinite. Nevertheless, there was no need for him to do so because we demonstrated briefly why they could not both be equally infinite. It was argued that every physical thing has a mental counterpart, if the will and the intellect, mind and body, or mental and physical were truly infinite, then each would be independent of the other. In other words, one could occur or exist without the other, which would also entail neither requiring the prior existence of the other.

Systems of belief herein mentioned referring to the mind and body as mental and physical do so through the notion of a property. A property may be considered to be anything that predicates or attributed to things and serves to characterize them (SEP, 2014). It was explained earlier why the physical could not be said to exist without the mental existing prior. Since most things physical do appear to have a mental precursor, the physical necessarily depends on the mental; however, the converse is not the case in that the mental does not depend on the physical.

The way in which the mental does not depend on the physical may be understood through the status of its existence. That something is physical implies that it exists as physical, but to talk of the nonphysical existing would be in the absence of evidence since no way to substantiate it would be possible. Either the mental is nonphysical, or the mental is physical; if the mental is indeed physical then it could be known as an extension or result of something bodily only after the body exists. 
On the other hand, if the property of mental is nonphysical, then proof of its existence by an individual whose property is physical would imply that both share at least one property. Furthermore, suppose that a person whose body has the attribute of physical, whatever the body may be said to cause will either be physical or nonphysical; if it is possible for the physical to cause the physical, then it is possible for the physical to be substantiated. If it is not possible for the physical to cause the physical, it is still possible to know that it is not possible because nothing physical would result. Moreover, regardless of whether or not it is possible for the physical to cause the nonphysical, it is not possible for the physical to substantiate the nonphysical one way or another. The implication is that

Suppose for a moment that a possible world exists. The existence of one individual in this possible world with no other living entity else would entail the following: the body of the person. Their body possesses the property of being physical. Furthermore, upon meditation and reflection similar to Descartes, the individual thinks and realizes that he or she is self-ware, which in turn allows them to recognize another property of their consciousness that is termed the mind, viz., that of the mental. It is through the mind that this person then perceives himself or herself to be the only being in this possible world.

The world is comprised of bodies that are physical (e.g., property). Self-awareness of the body through consciousness via the brain is termed the mind. However, a mind exists as a result of the body existing but does not share in the property of being physical. The basis for the claim that the mind is not physical is that none of the faculties of sense perception are called upon to know that a mind exists.

If it were to be imagined that a second person existed within the same possible world as the first, through the senses it could be concluded by the first individual that the second person exists. Furthermore, once a determination has been made that a second person exists, then it would also be concluded that is the second individual exists, then he or she has a mind. The mind may not be known through sense perception directly; it may only be known indirectly through the senses. Thus, it appears to be the senses of the body through which the mind may be appreciated. Nonetheless, the faculties of sight sound, taste, touch, and smell are mediated through the property of being physical. That is, physical properties are what permit knowledge of things (e.g., the mind) that do not share in the physical.

If it is granted that there may exist two distinct contradictory things as properties (i.e., physical and mental as nonphysical) that may be affirmed of one particular body, then because one body may be attributed both properties these properties must not be contradictory. In other words, to avoid an absurdity logically speaking, it must not be possible to derive one property and its converse from any single thing. If the previous statement is true, then humankind may be mistaken in its understanding and one of the following necessarily is the case: (1) the body is the common denominator for the two properties of the physical and the mental, or (2) the body is not the common denominator. By common denominator, it is meant that either the body would need to give rise to physical and mental properties which were not contradictions, the body would itself be a property common to both physical and mental entities, or that there is another property of the body that the physical and the mental all have in common (i.e., meta-property, or property of a property). Furthermore, it may be the case that there exists a symmetrical relation among properties such that if something is a property of another thing, then that something has that other thing as a property as well. The only faculty in which this relation holds is that for touch, which occurs via perception as feeling. For instance, without any additional qualification, it may be asserted that through the faculty of touch, if a feels $b$, then $b$ feels a. Although this is the case for touch, it is not necessarily true for any of the other four senses.

In the case of the body not having at least one attribute in common with both the physical and the mental (i.e., meta-property), (the body may be an attribute itself) it would be possible for the body to have knowledge of neither the physical nor the mental, knowledge of the physical, or knowledge of the mental; it would not be possible to know both. However, because knowledge of both the physical and the mental through the body is possible, at least one attribute links everything whether. What can be stated with certainty is that the body is the common denominator for the pair of properties. 
Furthermore, the body is the common denominator if and only if the properties of physical and mental are not contradictory.

Returning to the possible world, what may be inferred? There needs to be a world in which the person exists and the only way to determine the existence of a person or a world is through sharing at least one property. That is, if something were claimed to exist in a nonphysical, or immaterial form, then there would be no method of substantiating the existence of that something from the physical or material property perspective. Moreover, although pairwise opposites are required for there to be at least two forms of entity recognized (e.g., a property+ entity, and a property- entity), from the point of view of each respective entity, only an awareness that the opposite type of entity could exist is possible. The awareness is the only possible status because of the absence of any ability to confirm or deny such existence due to their dissimilar or different essences.

In the possible world with only one person, the individual's physical property of a body gives rise to mental properties of phenomena of the mind. However, if true that the person is both aware and can substantiate the existence of the mind, then the mind must share in a property of the body. That is, the mind and body may be physical, they may both be mental, or the physical and mental may have a property called "body."

Physical is suggested to be the core property of the existential condition according to the author. The basis for suggesting physical as the core property is that all other properties seem to be contingent on that of the physical. For instance, "is hard" as a predicated characteristic of a thing, relies on that thing also being attributed the property of physical. In fact, any manifested property of a thing requires sensory perception to assert or deny its existence, which means that the property of being physical is necessarily an attribute of this thing.

The reason the mind must also be physical is that in a physical or material reality, only an awareness that the nonphysical or immaterial may exist is possible. That two things have nothing in common implies that these thing cannot be understood through one another [9] (Spinoza, 1883). Furthermore, an absence of understanding is due to the inability from one perspective to know that the other exists because there can be no way to substantiate it. Thus, if true that a person may be able to substantiate the existence of something such as the mind, then that something necessarily shares in at least one property with the body. Furthermore, as was discussed, through the body's property of physical, having awareness and knowledge to substantiate the existence of the mind possessing the property of mental it would be reasonable to assume that the property shared is the core one of being physical because without it neither things that have physical nor those with mental properties could be perceived and known.

The mental extends beyond the physical the same way that the intellect must extend beyond the will. It may be concluded that the mental and physical, mind and body, will and intellect, are not the same as professed by Spinoza. Both Descartes and Spinoza are right, yet both are wrong; qualitative and quantitative characteristics explain how.

\section{The Qualitative-Quantitative Distinction}

Let us assume that the author presents to the reader an orange weighing five ounces and a lemon that weighed five ounces. If the author asked the reader to tell me how they are the same first and the tell me how they are different, what would the reader mention? The reader would state that they are fruit, citrus, have textured covering of skin, and weigh five ounces. Then, the reader would say that one is orange and the other yellow, one is sweet, and the other is sour, one is spherical, and the other elliptical, and one is spelled with six letters and the other five.

The statements regarding the orange and the lemon may be further divided and re-categorized into observations of immeasurable attributes (e.g., its essence), and those relating to measurable attributes. Doing so results in the following: they are the same because they are fruit, have textured skin, and because they are citrus (i.e., their essence). Also, they are the same because they weigh five ounces, and there is only one of each (i.e., measurable). Doing so again for the opposite: they 
are different because one is orange and one is yellow, one is spherical, and the other is elliptical, and one is sweet and the other sour (i.e., essence). Also, they are different because one is spelled with six letters and the other with five, and one is sweet and the other sour (i.e., measurable). The statements regarding observations of immeasurable attributes are qualitative characteristics while those of measurable attributes are quantitative characteristics.

Everything can be described in terms of both qualitative and quantitative characteristics. Moreover, sometimes the same attribute or characteristic may be categorized as both qualitative and quantitative. As an example, the author did not erroneously include sweet and sour twice. Both the sweetness of an orange and the sourness of a lemon differentiate them from one another as part of their essences. Although the sweetness of an orange and the sourness of a lemon are both part of their respective essential qualities, levels of sweetness are measured by the quantity of sugar and amount of sourness is measured by the quantity of acid and are quantitative characteristics as well. It has been seen how qualitative and quantitative dichotomy allows the discrimination between two things. As we continue the discussion concerning the will, comparison to freedom is made to gain further insight.

\section{Concerning the Will and Freedom}

The qualitative/quantitative dichotomy as a framework provides us with a lot of flexibility in addressing the will and the intellect. Upon reexamination, we can view the will and the intellect according to both Descartes and Spinoza in a different light. In fact, both were right about both the will and the intellect being different as well as the same. However, both were also wrong about them being both different and the same. That notwithstanding, being both correct and incorrect is not completely a contradiction thanks to the qualitative and quantitative dichotomy.

The will and intellect are indeed different qualitatively. That is, the will and intellect differ in that thoughts are not actions as the mind is not the body, and the mental is not the physical. The essence, immeasurable characteristic, or attribute, is not the same for both. Nevertheless, the will and the intellect may be considered the same quantitatively. In other words, their measurable characteristic or attribute is finite.

If the will and intellect were the same qualitatively, then thinking would be equivalent to acting or thoughts would be actions themselves. Additionally, if the acting were to result from a mere thought, we would not have a choice in the matter and be compelled to act without our consent. One could say that were this to be the state of things we would be completely determined. Even if we were to grant that the intellect, thinking, or thoughts, were a result of our will (e.g., freedom to choose), once we exercised our will to think we could not refrain from action despite our best effort.

To test this hypothesis, as one sits now on the couch one think about standing up so one should automatically rise to one's feet if it is true that mind and body, or mental and physical are the same. Unfortunately, once one had the thought, one finds oneself still reclined on the couch sitting. One willed the thought of the action of standing, yet one never even moved. One could use one's mind without one's body, one's mental without the corresponding physical.

The reader may also try this experiment to confirm that not only can one choose a thought, but he or she can also refrain from acting out the thought implying that they are separate and different. From this rudimentary experiment, one can determine that the mind and body, mental and physical, or will and intellect may not qualitatively the same as Spinoza believed.

Freedom of the will residing solely in what one thought, not whether one acted out, would render each qualitaitively indiscernible from the other. (Stanford ENCYCLOPEDIA of Philosophy, n.d.). One's behavior would be determined by their thoughts with no free will to refrain. Thus, to continue to speak of thoughts as different from actions would be to concede haecceitistical differences. Haecceitism allows for things to differ non-qualitatively yet exist qualitatively identical (Cowling, 2016). Without taking a stance to suppor or argue against it, merely assuming haecceitism I contend complicates the discourse regarding free will. There would be no purpose in discussion as non-qualitative differences between thought and action defy identification of free will's role in either. 


\section{An Alternate Theory for the Will and the Intellect:}

Concerning Descartes, as to whether we pass judgment on issues, which we have not sufficiently understood, the author must concede that this does lead to error. The simplest example of this can be found when confronted with a multiple-choice question where the author chooses an incorrect answer. The author did so because he did not wholly or clearly understand. According to Descartes, if the author did fully and clearly understand, then there would be no room for erring: there would only be one clear choice. He states that, with a clear understanding, there can only be one true choice. Based on the previous statement, one would have freedom to choose, yet he or she would not be indifferent. A lack of indifference would make one choose the correct answer each time, which in the author's interpretation, is not actually exercising freedom.

Freedom consists of actually being capable of doing one thing sometimes and doing another at different times; that is, the ability to do otherwise. However, if one were to possess a clear understanding of good, as Descartes states, then, he or she would always choose the correct answer. He or she could not choose the incorrect answer ever, although Descartes claims that he or she could. The problem is that there is no way to prove that one could indeed choose an incorrect answer since he or she would never choose one because he or she knows the right one. An inability to do so means one is not free at all. Therefore, he or she would not be truly free; he or she would be obligated to choose the correct one always.

If one were to follow up and ask this individual why he or she did not choose the "incorrect" or wrong answer or thing to do, he or she would respond "because it was wrong." If everyone were to be so inclined, then wrongdoing would never occur because he or she would be forced to do right. To always choose right or good is not true freedom. Consequently, although not necessarily the case that restrrictions on either liberty orr being determine affects te status of the other, under these circumstances, one would also be determined.

Both Descartes and Spinoza have arguments from which it has been deduced that our actions are determined. Either action is the same as, and determined by our thoughts with Spinoza, or in Descartes' case a true understanding always supersedes free will so that one can never truly do anything other than the right thing. Moreover, their respective views on the doctrine of the will are different, but they both state and, presumably agree on one thing: intellect before will.

Descartes believes that a perception on the part of the intellect must always precede a determination on the part of the will [5]. Spinoza says that one cannot affirm or deny anything without an idea, which implies that the idea must precede the affirming or denying. The two of them both agree on this. Nonetheless, this creates a dilemma for both.

For Descartes, he first asserts that the will, or affirming and denying, is infinite while the intellect is finite. Doing so would imply that the will can exist without the intellect, which is not true as we saw with the argument of Spinoza. Descartes encounters a problem by stating that a perception on the part of the intellect must precede a determination of the will. Without presupposing the existence of God, if the intellect must be first, and the will comes second, then, what caused the existence of the intellect? Something, which causes itself as well as something else, is infinite. Thus, the intellect must extend further than the will, and the will must be finite since the will needs the intellect. Furthermore, Descartes may have contradicted himself by saying that the will is infinite because it requires the intellect to precede it. Therefore, contrary to Descartes' assertion that it is infinite, the will appears to be finite and quantitatively the same as the intellect.

Spinoza states that the affirmation or denial must have an idea first. That is, without the idea, the affirmation or denial may not exist. The affirmation or denial that is the execution of the will is entirely dependent upon the idea of the intellect. Consequently, contrary to what Spinoza believes, the will and intellect cannot be the same. If they were the same, then either one would not depend on the other preceeding it, or each of them would have to depend on the other doing so. That notwithstanding, given Spinoza's own assertion that idea precedes affirmation or denial, the reason that both the will and the intellect could not each be equally required to precede the other is that it would not be possible 
for each one to function before the other yet have to wait for the other to precede it. Conversely, the other alternative is the only option for being the same. Unfortunately, however, if an idea would not have to precede an affirmation or denial unless an affirmation or denial would not have to precede an idea as well, then each would apparently operate independently of one another or at least be capable of doing so. Such independent operation would entail an ability to affirm or deny (i.e., will) in the absence of anything to affirm of deny, which is irrational to accept.

Spinoza says himself that the will is about the intellect. The author is in complete agreement with his argument that the will is not beyond the intellect. However, the author is not in agreement that it's equivalent to it. The author proposes that the intellect extends beyond the will but that both the will and intellect are finite, which adjudicates the theses of Descartes' and Spinoza's doctrines. Therefore, characteristics of the will and the intellect are qualitatively different but are quantitatively the same.

If the will has been shown not to extend beyond the intellect by Spinoza's argument that the affirmation or denial of an idea is the same as a perception and that the will and the intellect cannot be equivalent since one must precede the other as agreed upon by both Descartes and Spinoza, then it must follow that the intellect extends beyond the will. Although the intellect precedes the will as agreed upon by both philosophers, the author believes that there is a missing piece to the puzzle: that of something which precedes the intellect. Nevertheless, the intellect precedes the will, but only finitely and the author cannot say by how much it precedes, or extends.

It is worth taking a moment to articulate what is understood by the words finite and infinite since the concepts appear in both philosophers' arguments. The definition of finite as used in the context of this paper is: to require something outside of itself to exist before its existence. In addition, the definition of infinite as it is used for the purposes of this paper is: not to require something outside of itself to exist before its existence: can cause, or be the cause of its existence. It is important to note that the notion of infinite is understood by the author to be relative. The reason that it is understood in this manner is because .... In other words, what we understand as infinite with respect to us may itself be considered finite with respect to something else. For example, to an ant whose journey from the east coast to the west by foot, the ground may appear to be infinite. However, this relative process continues in an infinite regress.

The author neither wholly agrees with Descartes' assertion that the will is infinite and extends beyond the intellect because affirming or denying an idea is the same as perceiving it. the author also disagrees with Spinoza's assertion that both the will and the intellect are the same since ideas must precede an affirmation or denial. The author proposes that the intellect, since it must precede the will, must extend beyond it. Nevertheless, the author cannot state that the intellect is infinite because distinguishing between absolutely and relatively infinite from the standpoint of something finite is not possible. The author, therefore, concludes that the intellect extends beyond the will, but only finitely.

\section{Ontological Argument Against the Existence of Infinite Entities}

Ontology, from the Greek meaning "being," is the branch of Metaphysics devoted to what exists (Effingham, 2013). Having established with what we are concerned, we shall begin with the following assumptions: 1) that at least one entity exists with the attribute or characteristic property of being infinite that we shall refer to as an Infinite Entity and,2) that at least, one entity with the property of being Finite that we shall refer to as a Finite Entity exists as well. Let us also assume that finite entities require the existence of something other than themselves before their own existence. Additionally, an infinite entity does not require the prior existence of something other than itself; it can be the cause of its own existence.

From our assumptions, we can state that the infinite entity existed at some point before the finite entity did. Furthermore, when the infinite entity existed prior to any finite entity, it had to be the only 
entity that existed. Moreover, it being the only entity given our assumptions implies that it was the first to exist before all else.

While it is true that under normal circumstances being the only entity in existence does not preclude the possibility that entities existed before since finite entities cannot precede infinite ones, the only entity that could precede our infinite entity that we shall label $\mathrm{IE}_{n-1}$ would have to be infinite. Nonetheless, if there existed a preceding entity that was also infinite that we shall label $\mathrm{IE}_{n}$, then two issues arise. Firstly, the preceding infinite entity $\mathrm{IE}_{n}$ would not cease to exist, in which case instead of one infinite entity, there would be $\mathrm{IE}_{n}$ and subsequently $\mathrm{IE}_{n-1}$ implying the $\mathrm{IE}_{n-1}$ was not first. Secondly, if true there were an infinite entity $\mathrm{IE}_{n}$ that preceded our infinite entity $\mathrm{IE}_{n-1}$, then there was a point at which our infinite entity $\mathrm{IE}_{n-1}$ did not exist, which is also absurd if it is an infinite entity. Therefore, it is not possible to have multiple infinite entities sequentially since leads to absurdity. Moreover, if multiple infinite entities are impossible sequentially, then multiples at any point would be impossible as well. It is also not possible to have multiple infinite entities simultaneously since sharing in this characteristic qualitative, and quantitative property of infinite would render multiple entities one whole.

\section{Requisite Existence of Outside Entities}

Now that we understand how only implies first, it becomes obvious that before this infinite entity $\mathrm{IE}_{n-1}$ existed, nothing existed if one were to hold an affirmative propositional attitude toward the possibility of nothing. After $\mathrm{IE}_{n-1}$ exists, something exists. As we continue under the assumption that an infinite entity needs nothing outside of itself to precede its when nothing existed is the only point when $\mathrm{IE}_{n-1}$ could have caused or was the cause of its own existence. In other words, although by definition the infinite being does not need something outside of itself to precede its existence since only it can cause, or be the cause of its existence, $\mathrm{IE}_{n-1}$ had to exist before its own existence.

Regardless of what one calls it, anything that precedes $\mathrm{IE}_{n-1}$ must be something outside of $\mathrm{IE}_{n-1}$ that exists before $\mathrm{IE}_{n-1}$. For $\mathrm{IE}_{n-1}$, this would mean that something outside of itself existed before its existence because we are referring to before $\mathrm{IE}_{n-1}$ existed. Therefore, because $\mathrm{IE}_{n-1}$ requires something outside itself to exist prior to its own existence, $\mathrm{IE}_{n-1}$ is finite by definition, not infinite! We just showed that what we believed to be an infinite entity based on our premises is actually finite. Therefore, we must abandon the assumption that $\mathrm{IE}_{n-1}$ has the property of infinite and accept that $\mathrm{IE}_{n-1}$ must be finite.

This newly categorized finite entity, $\mathrm{IE}_{n-1}$, would always need something outside itself to exist before it actually exists itself. Insofar as our capacity to understand, whether $\mathrm{IE}_{n-1}$ could cause, or be the cause of, its own existence is highly doubtful. Even if we were tempted to claim that $\mathrm{IE}_{n-1}$ and $\mathrm{IE}_{n}$ were both infinite and identical to each other, this would be unlikely.

It is exceedingly problematic to accept $\mathrm{IE}_{n-1}$ and $\mathrm{IE}_{n}$ as identical and the very same entity, grant that there must have been a point prior to $\mathrm{IE}_{n-1}$ existing, but after $\mathrm{IE}_{n}$ exists, and reconcile both $\mathrm{IE}_{n-1}$ and $\mathrm{IE}_{n}$. To do so, perhaps, would require envisioning $\mathrm{IE}_{n-1}$ and $\mathrm{IE}_{n}$ being two fixed points at opposite ends of an IE spectrum that arcs outside of the realm of space-time at one end and re-enters space-time again at the other. Perhaps the arc would resemble the trajectory of a frog leaping from one lily pad to land on another. As opposed to a straight line from $\mathrm{IE}_{n}$ to $\mathrm{IE}_{n-1}$, the arcing is crucial because it allows for there to be a period of nonexistence as IE is beyond the realm of existence prior to the arrival of IE.

In fact, the points along the spectrum we are calling $\mathrm{IE}_{n}$ and $\mathrm{IE}_{n-1}$ may actually be points of convergence along one continuum. For instance, instead of the frog leap analogy, let us adopt something slightly different to clarify the point. Let us say that an infinite length of a single piece of yarn runs parallel to, and at the base of, an infinitely high and infinitely long wall that one were tasked with decorating. Your job would be to pick up the yarn with the index and thumb at random points and tack it on the wall. How high on the wall would one have to go before putting the tack on it? You would know to tack it when the two sides of the yarn get so close that they appear to be a single piece. Each tack on the wall would represent a unique IE convergence all from the same continuous IE 
string. The tacks represent points of existence, and the space between the tacks represent periods of non-existence.

Whether there is an actual IE that leaps in an arc from existing at one point to existing at another, or there is a single continuous IE string of yarn with convergence at points where $\mathrm{IE}_{n}$ and $\mathrm{IE}_{n-1}$ exist, $\mathrm{IE}_{n}$ precedes $\mathrm{IE}_{n-1}$ in an infinite regress (Cohen, 2005). Recall, finite entities require something outside themselves to exist before them, but even though infinite entities can cause, or be the cause of themselves, they need something outside themselves to exist before they exist just as finite entities do. For this reason, the author must conclude that there can only be one class of entity: finite. However, there must of necessity be an infinite number of preceding finite entities. Therefore, the author believes that infinite may refer only to an active process or series of changes and their derivatives, not an entity because the entity is singular and implies discontinuity, limitation, or boundaries that are not what a concept of infinite connotes.

\section{Counterintuitive Conclusion Regarding Infinite Processes}

In light of the previous statement regarding the appropriateness of infinite as a descriptor of processes or changes and not of that which undergoes them, the author asked himself the following: "Is it possible for something that continues in an infinite regress to have had a start?" To answer this, the author turns to numbers and the process of counting. As an example, whenever the author begins to count, the author can continue indefinitely. Moreover, the author can begin to count anywhere along the line of sequential numbers. However, we must concede that numbers don't count themselves. In other words, the author (i.e., finite entity) must initiate the process (of counting) with some number, but once the author does, the process of counting (i.e., infinite process) can go on perpetually. There appears to be something counterintuitive about anything infinite requiring a prerequisite in something finite.

No number encompasses all numbers, so numbers like all entities are finite. Like all finite entities, numbers can continue infinitely such that for any number, there is always one before and one that comes after. Interesting to note is that one can also never start the process of counting, but once one does, the process can continue forever regardless of whether the author lacks the ability to articulate numbers with known vocabulary. In addition, once the author starts this process, the author can always stop. So, if all entities, which we have previously concluded are finite, must have a starting point, then what causes these entities to become involved in perpetually ongoing processes and continue in them indefinitely? Furthermore, is it even plausible to conceive of a finite entity undergoing a process indefinitely? Finally, if at all possible, how can these infinite processes with finite entities be stopped since finiteness entails an end that contradicts the notion of an infinite process?

\section{Final Thoughts}

We initially defined finite and infinite according to whether something outside the entity itself was required before its existence and concluded that no infinite entities exist. What if we redefined them according to the ability to create something outside itself and ability to create itself? That is, a finite entity can only create something outside itself whereas an infinite entity can either create something outside itself or create itself. Does this rephrasing of the definition without altering the actual criteria allow us to avoid a contradiction or paradox?

Assuming it were possible to do, the ability for an entity to create itself is only useful for the first entity to come into existence; beyond that, it would serve no purpose. To repeatedly create itself would result in no progress toward any meaningful goal. However, creating something outside itself is beneficial and does not require it to be non-existent at any point. This requirement of nonexistence is a pivotal point in our thinking.

If we assume that an infinite entity exists in order for it to exist, then it required itself to exist before it actually exists, which means that when it exists before itself, it is something outside itself. If so, then creating itself doesn't require itself to go through non-existence to exist because, since it 
already exists anything it creates will be outside itself! So, because both the finite and infinite entities require something to exist outside themselves before their existence, there is no effective way to prove that it is possible to distinguish them from one another, which means that they either appear to be or are, qualitatively the same!

Rephrasing the definitions in terms of the ability to create, instead of what was required for them to be created, allowed us to clearly see how there can only be one entity class from the perspective of a finite entity. Furthermore, even if it were possible for an infinite entity to exist, it would not only have to exist before all else but because it had to there could never be any way for there to exist a distinct simultaneous or subsequent entity, finite or infinite, for all eternity. The entity would be continuous with everything that exists at any point making the existence of more than one entity impossible. Moreover, were we to persist in this belief that an infinite entity could coexist distinct from a finite entity, there would absolutely be no way to tell it apart from the finite entity since both create something outside themselves - even in the case of a hypothetical infinite entity that creates itself. Therefore, the author holds firm in the conclusion that only finite entities exist and, as finite entities, the closest that we may come in our ability to conceive of an entity that remotely approaches being infinite is to contemplate procreational abilities possessed by humankind and all creatures that derive existence through living.

14.

Blackburn, S.(2016). epistemology. In The Oxford Diconary of Philosophy. : Oxford University res. etrived 8 Jan. 2017, from http://www.oxfordreference.com/view/10.1093/acref/9780198735304.0 01.0001/acref-9780198735304-e-1113.

Blackburn, S.(2008). metaphysics. In The Oxford Dictionary of Philosophy. : Oxford University Press. Retrieved 8 Jan. 2017, from http:/ / www.oxfordreference.com/view/10.1093/acref/9780199541430.00 1.0001/acref-9780199541430-e-2010.

Blackburn, S.(2008). rationalism. In The Oxford Dictionary of Philosophy. : Oxford University Press. Retrieved 8 Jan. 2017, from http:/ / www.oxfordreference.com/view/10.1093/acref/9780199541430.00 1.0001/acref-9780199541430-e-2636

Cahn, S. M. (1995). Classics of western philosophy (4th ed.). Indianapolis, NY: Hacket Pub. Co. Calef, S. (n.d.). Dualism and Mind I Internet Encyclopaedia of Philosophy. Retrieved from http://ww w.iep.utm.edu/dualism/

Cohen, M.(2005). infinite regress. In The Oxford Companion to Philosophy. : Oxford University Press. Retrieved 8 Jan. 2017, from http:/ /www.oxfordreference.com/view/10.1093/acref/9780199264797.00 1.0001 /acref-9780199264797-e-1224.

Effingham, N. (2013). An Introduction to Ontology ip. 1 online resource (183 pages)). Retrieved from Ebook Library http:/ /NY3R.eblib.com/patron/FullRecord.aspx?p=1366273

Blackburn, S.(2016). epistemology. In The Oxford Diconary of Philosophy. : Oxford University res. etrived 8 Jan. 2017, from http:/ / www.oxfordreference.com/view/10.1093/acref/9780198735304.0 01.0001/acref-9780198735304-e-1113.

Blackburn, S.(2008). metaphysics. In The Oxford Dictionary of Philosophy. : Oxford University Press. Retrieved 8 Jan. 2017, from http://www.oxfordreference.com/view/10.1093/acref/9780199541430.00 1.0001/acref-9780199541430-e-2010.

Blackburn, S.(2008). rationalism. In The Oxford Dictionary of Philosophy. : Oxford University Press. Retrieved 8 Jan. 2017, from http://www.oxfordreference.com/view/10.1093/acref/9780199541430.00 1.0001/acref-9780199541430-e-2636

Cahn, S. M. (1995). Classics of western philosophy (4th ed.). Indianapolis, NY: Hacket Pub. Co. Calef, S. (n.d.). Dualism and Mind I Internet Encyclopaedia of Philosophy. Retrieved from http://ww w.iep.utm.edu/dualism/

Cohen, M.(2005). infinite regress. In The Oxford Companion to Philosophy. : Oxford University Press. Retrieved 8 Jan. 2017, from http://www.oxfordreference.com/view/10.1093/acref/9780199264797.00 
1.0001/acref-9780199264797-e-1224.

Effingham, N. (2013). An Introduction to Ontology ip. 1 online resource (183 pages)). Retrieved from Ebook Library http:/ /NY3R.eblib.com/patron/FullRecord.aspx?p=1366273

15.

\section{References}

1. (n.d, O.R. Philosophy -; Oxford.

2. Effingham, N. An Introduction to Ontology ip. 1 online resource; Retrievedfrom Ebook Library, 2013.

3. Blackburn. metaphysics. In The OxfordDictionary of Philosophy; Oxford University Press, 2008.

4. Blackburn. epistemology. In The OxfordDictionary of Philosophy; Oxford University Press, 2016.

5. Cahn, S.M. Classics of westernphilosophy; Hacket Pub. Co: Indianapolis, NY, 1995.

6. (n.d Calef, S. Dualism and Mind I InternetEncyclopaedia of Philosophy.

7. Zupko, J. The Stanford Encyclopedia of Philosophy (Fall2018). MetaphysicsResearch, 2018.

8. Schaffer, J. "Monism (Stanford Encyclopediaof Philosophy)." Stanford Encyclopedia of Philosophy.

9. Spinoza, B. Ethic demonstrated in geometricalorder: And divided into five parts, which treat I. Of God. II. Of the natureand origin of the mind. III Of the nature $\mathcal{E}$ origin of the affects. IV. Ofhuman bondage, or of the strength of the affects. V. Of the power of theintellect, or of human liberty; Macmillan: New York, NY, 1883.

\section{Author biography}

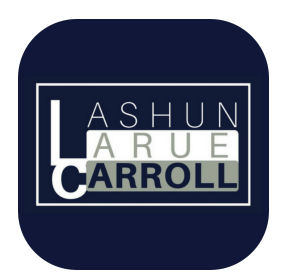

La Shun L. Carroll La Shun L. Carroll obtained his Ed.M. from the University at Buffalo Graduate School of Education after earning his Doctorate, Cum Laude from the University at Buffalo School of Dental Medicine. Dr. Carroll obtained his B.A., graduating Magna Cum Laude, majoring in Philosophy from Baruch College. His publications include "Theoretical Biomimetics: A biological design-driven concept for creative problem-solving as applied to the optimal sequencing of active learning techniques in educational theory" in Multidisciplinary Journal for Education, Social and Technological Sciences (October 2017), and "A Comprehensive Definition of Technology from an Ethological Perspective" (MDPI, 2017). Research interests include metaphysics, logic, science, technology, and education. Dr. Carroll was an Adjunct Professor at Saint Michael's College. 